\title{
The potential to encode sex, age, and individual identity in the alarm calls of three species of Marmotinae
}

\author{
Vera A. Matrosova • Daniel T. Blumstein • \\ Ilya A. Volodin • Elena V. Volodina
}

Received: 26 August 2010 /Revised: 29 November 2010 / Accepted: 16 December 2010/Published online: 8 January 2011

(C) The Author(s) 2011. This article is published with open access at Springerlink.com

\begin{abstract}
In addition to encoding referential information and information about the sender's motivation, mammalian alarm calls may encode information about other attributes of the sender, providing the potential for recognition among kin, mates, and neighbors. Here, we examined 96 speckled ground squirrels (Spermophilus suslicus), 100 yellow ground squirrels (Spermophilus fulvus) and 85 yellowbellied marmots (Marmota flaviventris) to determine whether their alarm calls differed between species in their ability to encode information about the caller's sex, age, and identity. Alarm calls were elicited by approaching individually identified animals in live-traps. We assume this experimental design modeled a naturally occurring predatory event, when receivers should acquire information
\end{abstract}

\footnotetext{
V. A. Matrosova $\cdot$ I. A. Volodin

Department of Vertebrate Zoology, Faculty of Biology,

Lomonosov Moscow State University,

Vorobievy Gory, 12/1,

Moscow 119991, Russia

V. A. Matrosova

e-mail: v.matrosova@gmail.com

D. T. Blumstein

Department of Ecology and Evolutionary Biology,

University of California,

621 Young Drive South,

Los Angeles, CA 90095-1606, USA

e-mail: marmots@ucla.edu

I. A. Volodin $(\bowtie) \cdot$ E. V. Volodina

Scientific Research Department,

Moscow Zoo,

B. Gruzinskaya, 1,

Moscow 123242, Russia

e-mail: volodinsvoc@gmail.com

E. V. Volodina

e-mail: volodinsvoc@mail.ru
}

about attributes of a caller from a single bout of alarm calls. In each species, variation that allows identification of the caller's identity was greater than variation allowing identification of age or sex. We discuss these results in relation to each species' biology and sociality.

Keywords Marmota flaviventris · Spermophilus fulvus . Spermophilus suslicus · Alarm call · Acoustic communication · Antipredator behavior

\section{Introduction}

While mammalian and avian alarm calls function to reduce predation risk to the caller or conspecifics, there is additional acoustic variation that may provide information about the caller's attributes (Rendall et al. 2009). In many mammals, vocalizations encode information about the caller's sex, age, or identity (e.g., Leger et al. 1984; Cheney and Seyfarth 1990; Durbin 1998; Frommolt et al. 2003; Torriani et al. 2006). Within-species variation of acoustic signals provides a potential for recognition among kin, mates, and neighbors. Between-species variation may be related to species-specific social structures.

Among ground-dwelling sciurid rodents, alarm calls are the most prominent acoustic signal. Besides their primary functions of warning conspecifics of predators (Sherman 1977; Blumstein 2007), or informing predators that they have been detected (Woodland et al. 1980; Sherman 1985; Hasson 1991; Shelley and Blumstein 2005; Digweed and Rendall 2009a, b), alarm calls of ground-dwelling sciurids may provide concomitant information about the caller's sex, age, and identity. Individual-specific alarm calls were reported for steppe marmots Marmota bobak (Nikol'skii and Suchanova 1994), Belding's ground squirrels Spermo- 
philus beldingi (Leger et al. 1984; McCowan and Hooper 2002), yellow-bellied marmots Marmota flaviventris (Blumstein and Munos 2005), speckled ground squirrels Spermophilus suslicus (Volodin 2005; Matrosova et al. 2009), yellow ground squirrels Spermophilus fulvus (Matrosova et al. 2010a, b), European ground squirrels Spermophilus citellus, and Taurus ground squirrels Spermophilus taurensis (Schneiderová and Policht 2010). In Richardson's ground squirrels Spermophilus richardsonii (Hare 1998) and yellow-bellied marmots (Blumstein and Daniel 2004), playbacks demonstrated the ability to distinguish among calls of familiar and unfamiliar individuals.

Sex differences were found in alarm calls of yellow-bellied marmots (Blumstein and Munos 2005), but not in speckled ground squirrels (Volodin 2005). Age-related features were found in alarm calls of black-tailed prairie dogs Cynomys ludovicianus (Owings and Loughry 1985), steppe marmots (Nesterova 1996; Nikol'skii 2007), yellow-bellied marmots (Blumstein and Munos 2005), little ground squirrels Spermophilus pygmaeus (Nikol'skii 2007), and speckled ground squirrels (Volodina et al. 2010), but not in Richardson's ground squirrels (Swan and Hare 2008) or yellow ground squirrels (Volodina et al. 2010). Consistently, playback studies revealed distinctive responses to alarm calls of adults and pups in California ground squirrels Spermophilus beecheyi (Hanson and Coss 2001), yellow-bellied marmots (Blumstein and Daniel 2004) and steppe marmots (Nesterova 1996), but not in Richardson's ground squirrels (Swan and Hare 2008).

Thus, ground-dwelling sciurids represent a convenient group for determining what kinds of acoustic parametersfrequency, temporal, or amplitude (or combinations of them) - are responsible for encoding and decoding specific information (e.g., a caller's identity, sex, or age). Furthermore, by examining to which extent alarm calls differ between individuals, the sexes, and age classes among different species of Marmotinae, we can determine the relative importance of these cues for different species in relation to their biology and sociality.

To date, the relative contribution of different acoustic variables to the discrimination of age, sex, and identity has been studied in detail only for a single species, the yellowbellied marmot (Blumstein and Munos 2005). The current study expands on this study to focus on interspecific variation in ratios of age, sex, and individual variability of the yellow-bellied marmot and of two species of Spermophilus ground squirrels, where the first species, S. fulvus, is of comparable size and sociality as yellow-bellied marmots (Tchabovsky 2005; Matrosova et al. 2010a), and the second one, S. suslicus, is much smaller and less social than both species (Tchabovsky 2005; Matrosova et al. 2009).

$S$. fulvus is the largest ground squirrel. It inhabits open steppe and desert habitats with patchy grasses. Individuals place their burrows on local topographic features (Kashkarov and Lein 1927; Ismagilov 1969) which permits group members to monitor each other. This visibility may favor its relatively advanced sociality compared to the smaller Spermophilus species (Tchabovsky 2005). Sociality they are characterized by having: (1) a male hierarchy during the mating period (Bokshtein et al. 1989); (2) social play that occurs between littermates, and (3) affiliative motheroffspring contacts from emergence to their first hibernation (Vasilieva et al. 2009). Like marmots (Armitage 1999), many female $S$. fulvus hold the same home territories for years, and this results in stable local groups based on female kinship (Shilova et al. 2006; Matrosova et al. 2008; Vasilieva et al. 2009). While $M$. flaviventris are among the least-social species of marmots (Armitage 1991), S. fulvus and M. flaviventris are similarly social in that females form groups based on kinship and young disperse at yearlings, rather than as juveniles.

By contrast, S. suslicus do not form groups based on female kinship, pups disperse as juveniles, and the species is relatively small compared with other ground squirrels (Tchabovsky 2005). They live in relatively closed habitats, covered with high grasses that block visibility during much of their active season (Volodin et al. 2008).

We hypothesized that alarm calls of more social species should provide more cues about caller identity because there is a greater need for individual discrimination within social groups in more social species. Also, we expected more cues about age and sex in the more social species, as these are features related to different social roles in sciurids (Blumstein and Armitage 1997). The purpose of this study was to identify acoustic correlates of the caller's identity, sex, and age in these three sciurid species and to examine the relationships between these acoustic cues and features of social organization.

\section{Materials and methods}

Subjects and study sites

We recorded alarm calls from three species. Our subjects were 52 adult and 44 juvenile $S$. suslicus, 50 adult and 50 juvenile $S$. fulvus and 38 adult and 47 juvenile $M$. flaviventris. $S$ suslicus were recorded in the Moscow region, Russia $\left(54^{\circ} 47^{\prime} 68^{\prime \prime} \mathrm{N}, 38^{\circ} 42^{\prime} 23^{\prime \prime} \mathrm{E}\right), S$. fulvus in the Saratov region, Russia $\left(50^{\circ} 43^{\prime} 88^{\prime \prime} \mathrm{N}, 46^{\circ} 46^{\prime} 04^{\prime \prime} \mathrm{E}\right)$, and $M$. flaviventris were recorded in the Upper East River Valley, Gunnison County, Colorado, USA ( $\left.38^{\circ} 57^{\prime} \mathrm{N}, 106^{\circ} 69^{\prime} \mathrm{W}\right)$. Marmots at this Colorado site have been studied continuously since 1962 (Armitage 1991); both ground squirrel colonies have been studied since 2001. All animals were individually marked and repeatedly captured in live-traps. Detailed methods of animal trapping and marking can be 
found in Armitage (1982), Blumstein and Munos (2005) for the marmots, and Matrosova et al. (2007, 2009, 2010a) for ground squirrels. For this study, the "adult" age class included animals that were in their second season of life, and "juveniles" were pups that emerged from their natal burrows during the year of data collection.

\section{Data collection}

We recorded alarm calls of $M$. flaviventris from JuneAugust 2001-2003. S. suslicus were recorded from MayJune 2003-2006. S. fulvus were recorded from May-June 2005-2008. The recordings were made during the season of pup raising in all the species. Alarm calls were recorded from individually marked animals of known age and sex sitting in wire-mesh traps, within $1 \mathrm{~h}$ of capture. Marmot alarm calls were recorded $20-40 \mathrm{~cm}$ from calling subjects; S. suslicus calls were recorded about $30 \mathrm{~cm}$; and S. fulvus calls were recorded about $100 \mathrm{~cm}$ from calling subjects. This variation in the distance to microphone among species was related to differences in relative call loudness and was sufficiently far to avoid near-field effects. Animals emitted alarm calls toward humans spontaneously or in response to additional stimulation (movements of hand-held hats). Calls elicited in live-traps in response to humans are similar to naturally elicited alarm calls (Blumstein and Munos 2005; Matrosova et al. 2007, 2010b). Subjects were weighed after recording their calls $(1 \mathrm{~g}$ precision for squirrels and $25 \mathrm{~g}$ precision for marmots).

Calls were recorded using either a Marantz PMD-222 analog tape recorder with an AKG-C1000S cardioid electret condenser microphone (frequency response, $40 \mathrm{~Hz}-$ $14 \mathrm{kHz}$ ), a CF-recorder Marantz PMD-671 with a Sennheiser K6 ME-64 cardioid electret condenser microphone (frequency response, $40 \mathrm{~Hz}-24 \mathrm{kHz}$, sampling rate $48.0 \mathrm{kHz}$ ), with digital audio tape decks Sony PCM-M1 or Tascam DA-P1 (sampling rate $44.1 \mathrm{kHz}$ ) and Audix OM-3 $\mathrm{xb}$ microphones (frequency response, $40 \mathrm{~Hz}-$ $20 \mathrm{kHz}$ ). The frequency response curves of all microphones were flat over the whole range of the spectra of the alarm calls recorded, thus the use of different types of recording equipment did not confound our acoustic measurements. For data transferring and further acoustic analyses, we used a MOTU 828 Firewire external digital board (Mark of the Unicorn, Cambridge, MA, USA) with a Macintosh PowerBook G4 (Apple computer, Cupertino, CA, USA) and Canary 1.2.4 (Charif et al. 1995), Sound-Edit 16 (Macromedia 1995), and Avisoft SASLab Pro v. 4.3 (Avisoft Bioacoustics, Berlin, Germany) software. For both Spermophilus species, calls were digitized at $24 \mathrm{kHz}$ sampling frequency and 16-bit precision and high-pass filtrated at $1 \mathrm{kHz}$ to remove background noise. For M. flaviventris, calls were digitized at $44.1 \mathrm{kHz}$ sampling frequency and 16-bit precision and not filtered. For all species, spectrograms for analysis were created using Hamming window, Fast Fourier transform length 1,024 points, frame 50\%, and overlap $96.87 \%$.

\section{Call analysis}

For all species, we analyzed calls from a single recording session per animal (first session, when more than one recording session per animal was available). We took measurements (Table 1) from ten randomly selected alarm call notes of good quality (not superimposed with wind or noise) per ground squirrel and from alarm call notes per marmot (12 animals provided fewer notes; four S. suslicus provided seven to eight notes, seven $S$. fulvus provided six

Table 1 Variables of alarm calls of three species of Marmotinae: speckled ground squirrel S. suslicus, yellow ground squirrel $S$. fulvus, and yellow-bellied marmot M. flaviventris

\begin{tabular}{|c|c|c|}
\hline Variable & Description & Species \\
\hline fo $\max$ & The maximum fundamental frequency of a note $(\mathrm{kHz})$ & All \\
\hline fo st & The fundamental frequency at the start of a note $(\mathrm{kHz})$ & All \\
\hline fo end & The fundamental frequency at the end of a note $(\mathrm{kHz})$ & All \\
\hline fo $\min$ & The minimum fundamental frequency of a note $(\mathrm{kHz})$ & S. suslicus, $M$. flaviventris \\
\hline fo centre & The fundamental frequency in the middle of a note $(\mathrm{kHz})$ & S. suslicus \\
\hline f peak & The maximum amplitude frequency of a note $(\mathrm{kHz})$ & S. suslicus, M. flaviventris \\
\hline$q 25$ & The value of the first energy quartile of a second note in a cluster $(\mathrm{kHz})$ & S. fulvus \\
\hline bnd & The width of maximum amplitude frequency band at $-20 \mathrm{~dB}(\mathrm{kHz})$ & S. suslicus, M. flaviventris \\
\hline duration & Total duration of a note (ms) & S. suslicus, M. flaviventris \\
\hline dur st-max & The time period from the beginning to the point of maximum fundamental frequency of a note (ms) & S. fulvus \\
\hline dur max-end & The time period from the point of maximum fundamental frequency to the end of a note (ms) & S. fulvus \\
\hline$d$ ampl & The difference between the amplitudes of fundamental frequency and first harmonic bands (dB) & M. flaviventris \\
\hline period $1-2$ & The time period from the start of a first note to the start of a second note in a cluster (ms) & S. fulvus \\
\hline df $\max 1-2$ & The difference between the maximum fundamental frequencies of a first and of a second note in a cluster $(\mathrm{kHz})$ & S. fulvus \\
\hline
\end{tabular}


Fig. 1 Spectrograms and mean power spectra illustrating the measured variables in three species of Marmotinae: a speckled ground squirrels $S$. suslicus; b yellow ground squirrels S. fulvus; and c yellow-bellied marmots $M$. flaviventris). For designations see Table 1
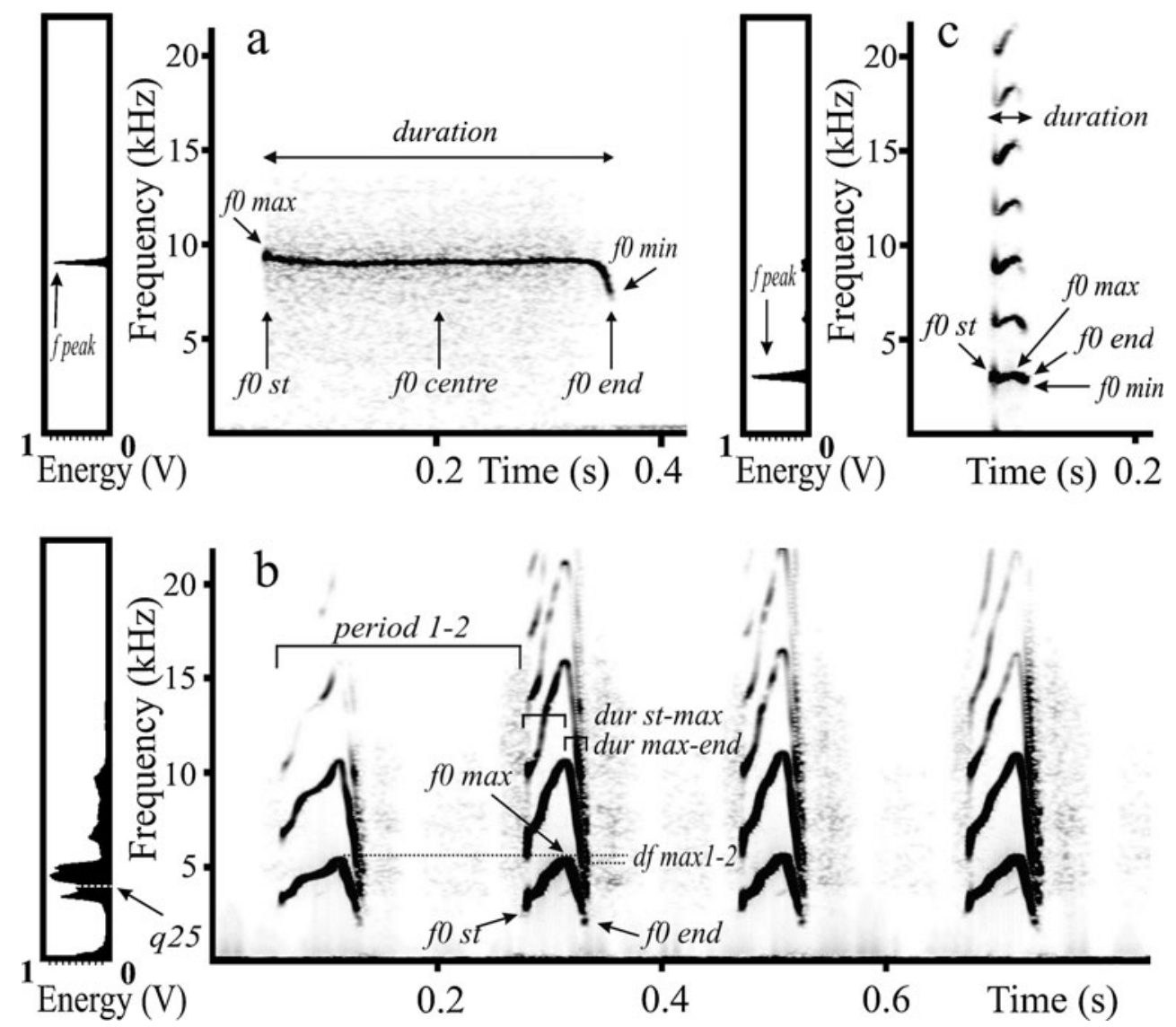

to nine notes, one $M$. flaviventris provided four notes). In total, we analyzed 949 alarm calls from 96 S. suslicus (514 from adults, 435 from juveniles), 984 alarm calls from 100 S. fulvus (497 from adults, 487 from juveniles), and 424 alarm calls from 85 M. flaviventris (190 from adults, 234 from juveniles).

In S. suslicus and M. flaviventris, alarm calls are single notes, weakly modulated in frequency, so it was difficult to determine a position of $f 0$ maximum visually (Fig. 1). We used the "automatic parameter measurements" option of Avisoft SASLab Pro or waveforms in Canary to extract the fundamental frequency values $(f 0 \max , f 0$ st, $f 0 \max , f 0$ end,
fO centre) and duration of each alarm call note (see Blumstein and Munos 2005 and Matrosova et al. 2007, 2009 for measurement details). From the mean power spectrum, we measured the f peak of a call note, $d$ ampl and bnd (see Table 1 for description of all variables).

S. fulvus alarm calls represent clusters of two to 16 notes, deeply modulated in frequency, so the $f 0 \max$ was clearly visible and had the highest energy relative to the harmonics (Fig. 1). Thus, for this species we measured $f 0 \max , f 0$ st, $f 0$ max, and $f 0$ end (Table 1) of a note directly from the screen with the reticule cursor (see Matrosova et al. 2007, 2010a, b for measurement details). Since many clusters consisted of
Table 2 GLMM results for effects of factors "sex", "age", and "identity" on the alarm call variables in speckled ground squirrels $S$. suslicus

$F-F$-ratios of GLMM.

Significant effects are given in bold

${ }_{*}-p<0.05, * *-p<0.01$,

$* * *-p<0.001$

\begin{tabular}{llll}
\hline Variable & \multicolumn{2}{l}{ Factor } & \\
\cline { 2 - 4 } & Sex & Age & Identity \\
\hline Duration & $F_{1,853}=1.38 ; p=0.24$ & $\boldsymbol{F}_{\mathbf{1 , 8 5 3}}=\mathbf{5 . 2 7 *}$ & $\boldsymbol{F}_{\mathbf{9 3 , 8 5 3}}=\mathbf{3 8 . 1 9 * * *}$ \\
f0 st & $F_{1,853}=0.002 ; p=0.97$ & $F_{1,853}=0.75 ; p=0.39$ & $\boldsymbol{F}_{\mathbf{9 3 , 8 5 3}}=\mathbf{1 4 9 . 4 1 * * *}$ \\
f0 centre & $F_{1,853}=0.13 ; p=0.72$ & $F_{1,853}=0.60 ; p=0.44$ & $\boldsymbol{F}_{\mathbf{9 3 , 8 5 3}}=\mathbf{1 7 6 . 2 3 * * *}$ \\
f0 end & $F_{1,853}=0.28 ; p=0.60$ & $F_{1,853}=3.13 ; p=0.08$ & $\boldsymbol{F}_{\mathbf{9 3 , 8 5 3}}=\mathbf{6 4 . 9 6 * * *}$ \\
$f 0$ max & $F_{1,853}=0.11 ; p=0.75$ & $F_{1,853}=2.54 ; p=0.11$ & $\boldsymbol{F}_{\mathbf{9 3 , 8 5 3}}=\mathbf{2 3 2 . 0 1 * * *}$ \\
$f 0$ min & $F_{1,853}=0.16 ; p=0,69$ & $F_{1,853}=0.62 ; p=0.43$ & $\boldsymbol{F}_{\mathbf{9 3 , 8 5 3}}=\mathbf{5 9 . 8 9 * * *}$ \\
f peak & $F_{1,853}=0.10 ; p=0.76$ & $F_{1,853}=0.64 ; p=0.43$ & $\boldsymbol{F}_{\mathbf{9 3 , 8 5 3}}=\mathbf{1 7 0 . 8 5 * * *}$ \\
bnd & $F_{1,853}=0.01 ; p=0.93$ & $\boldsymbol{F}_{\mathbf{1 , 8 5 3}}=\mathbf{9 . 3 9 * *}$ & $\boldsymbol{F}_{\mathbf{9 3 , 8 5 3}}=\mathbf{1 0 . 6 2 * * *}$ \\
\hline
\end{tabular}


only two notes, and the first note in a cluster was often more variable than subsequent notes, we fully measured the second note. From mean power spectra, we automatically measured $q 25$. We calculated dur st-max and dur max-end (Table 1). Also, for each cluster, we measured period 1-2 and calculated $d f \max 1-2$ (Table 1).

a

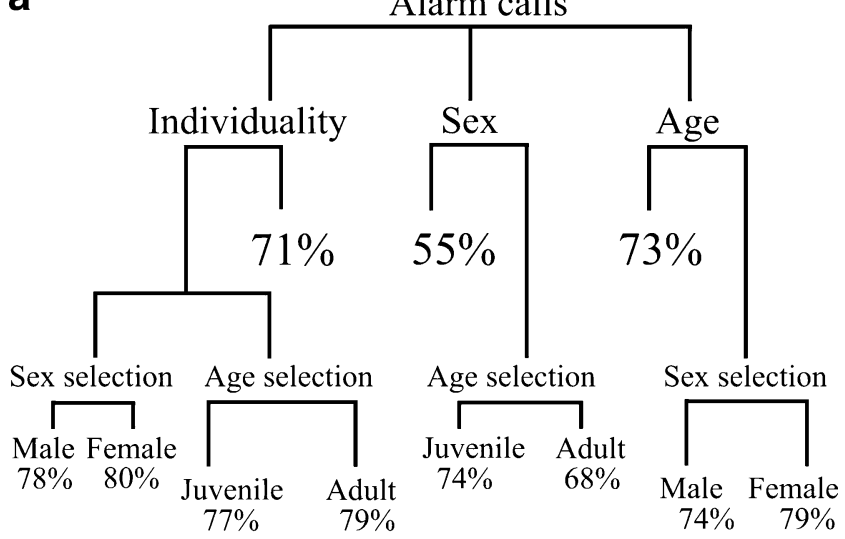

b

b Alarm calls

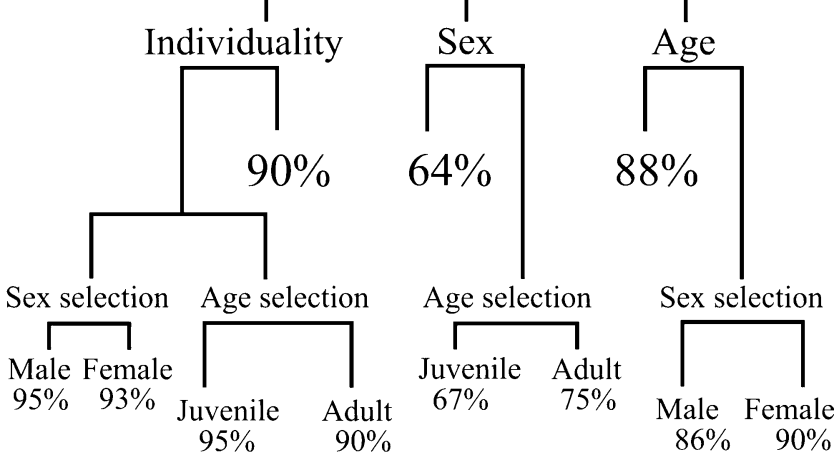

C

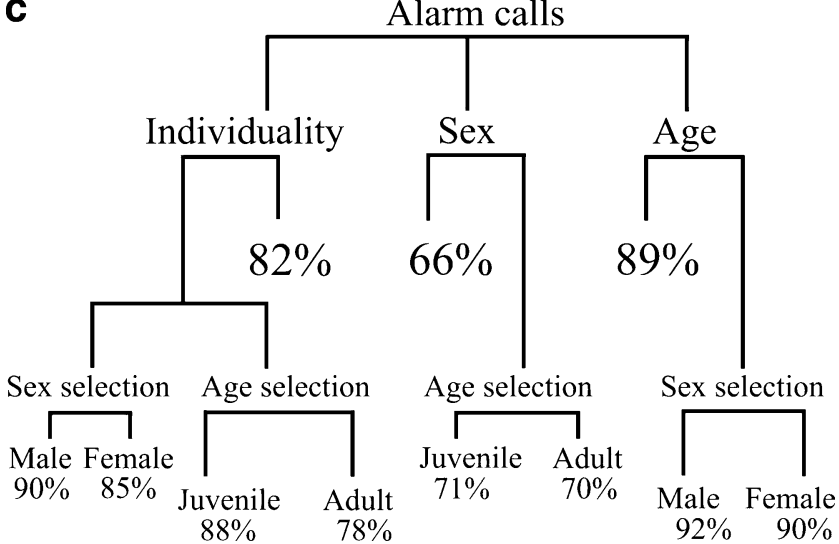

Fig. 2 Schematic representation for DFA values of correct assignment of alarm calls to individual, sex, and age: a speckled ground squirrels S. suslicus, $N=96$ animals; b yellow ground squirrels $S$. fulvus, $N=100$ animals; c yellow-bellied marmots $M$. flaviventris, $N=85$ animals
For each species, we measured eight acoustic variables (Fig. 1, Table 1) and used two rules to select variables. First, we wished to minimize the correlation among variables, and second, we wished to maximize the potential for discrimination among individuals. For S. suslicus and $S$. fulvus, we selected the eight variables that were the least correlated of (respectively) 31 and 18 variables on the basis of principal component analyses. For these species, these variables also had the largest $F$-values in ANOVA on individual identity (Matrosova et al. 2010a). For $M$. flaviventris, we selected eight variables that were useful for individual discrimination (Blumstein and Munos 2005). By selecting variables to maximize individual discrimination, we could potentially enhance the individual discrimination compared with sex and age discrimination. However, this effect should be equal for all the three study species and is in no way confounding.

Statistics

All statistical analyses were conducted using STATISTICA, v. 6.0 (StatSoft, Tulsa, OK, USA). All tests were two-tailed, and differences were considered significant whenever $p<0.05$. We used parametric tests, after determining that parameter values approximated normal distributions (KolmogorovSmirnov test, $p>0.05$ ). To estimate the effects of factors "sex", "age", and "identity" on the alarm call structure, we fitted General Linear Mixed Models (GLMM), with "sex" and "age" as fixed factors and "identity" as a random factor. Identity was preliminarily nested into the factors "sex" and "age"". This statistical design allowed us to estimate the effect of identity without effects of sex and age of a particular individual. Using discriminant function analysis (DFA), we calculated the values of correct assignment of alarm calls to individual, sex, or age. In each DFA, we used all eight measured variables per species and estimated the relative importance of these variables for discrimination using Wilks' lambda values. We used $\chi^{2}$ test to compare the obtained values of correct assignment to individual or sex-age group.

To validate DFA results, we calculated the random values of correct assignment to individual, sex, and age for each species using randomization procedure with 300 permutations (Solow 1990) with macros, created for STATISTICA. Using a distribution obtained by the permutation, we noted whether the observed value exceeded $95 \%$ or $99 \%$ of the values within the distribution (Solow 1990; Matrosova et al. 2010a, b).

We used DFA results to compare the degree of individual-, sex-, and age-related characteristics in the alarm calls of three species because DFA results depend primarily on the number of groups (individuals in the current analyses) analyzed and on the number of variables 
on which the classification is based (Hurlburt 2003). In the current study, samples of individuals were large (to provide the high inter-group variability) and nearly equal $(85,96$, and 100 individuals), and the number of acoustic variables included into DFA (Table 1) were equal.

\section{Results}

Speckled ground squirrels (S. suslicus)

Table 2 presents GLMM results for effects of factors "sex", "age", and "identity" on the alarm call variables in the $S$. suslicus. We found strong effects of caller identity on all alarm call parameters. The effects of age were significant only for two parameters, and no effects of sex were found (Table 2).

A DFA classifying alarm calls to sex correctly assigned $54.8 \%$ of the calls (Fig. 2a) that did not significantly exceed the random value $(53.6 \%)$. A separate DFA for adults correctly assigned $67.9 \%$ to sex, and a separate DFA for pups correctly assigned $74.5 \%$ to sex. In order of decreasing importance, the $f 0 \mathrm{st}$, duration, bnd, and $f 0$ max were mainly responsible for discrimination.

A DFA classifying alarm calls to age correctly assigned $73.1 \%$ to age (Fig. 2a) that significantly exceeded $(p<0.01)$ the random value $(54.9 \%)$. A separate DFA for males correctly assigned $74.0 \%$ to age, and a separate DFA for females correctly assigned $79.1 \%$ to age. In order of decreasing importance, the duration, $f 0$ max, $f 0$ end, and fo min were mainly responsible for discrimination.

A DFA classifying alarm calls to individual correctly assigned $71.2 \%$ of the calls (Fig. 2a) that did significantly exceed $(p<0.01)$ the random value $(5.7 \%)$. A separate DFA for adults correctly assigned $79.2 \%$ to individual; a separate DFA for pups correctly assigned $77.5 \%$ to individual; a separate DFA for males correctly assigned $77.9 \%$ to individual, and a separate DFA for females correctly assigned $79.5 \%$ to individual. In order of decreasing importance, the duration, fo end, fo st, and bnd were mainly responsible for discrimination.

Therefore, in S. suslicus, assignment to sex did not differ from the random value; assignment to age was 1.5 times the random value, and assignment to individual was 12 times the random value. Figure 2a summarizes the DFA results for within-species variation of alarm calls in $S$. suslicus. Moreover, some parameters that were the most important ones for age or sex discrimination were also the most important ones for individual discrimination. The duration was among variables of most importance in all three DFAs. This suggests that sex- and age-related variation in call structure was based on the same acoustic cues, and these were also used for individual-level discrimination. Table 3 presents descriptive statistics for alarm call variables included into DFA and body weight for two age classes and two sex/gender classes of the $S$. suslicus.

\section{Yellow ground squirrels (S. fulvus)}

Table 4 presents GLMM results for effects of factors "sex", "age", and "identity" on alarm call variability in S. fulvus. We found significant effects of identity on all variables. We found significant effects of age on seven of the eight variables; however, only three of these effects were comparable to the effects of identity. Effects of sex were significant for three of the eight variables, but these effects were much weaker than effects of age and especially caller identity.

A DFA classifying alarm calls to sex correctly assigned $64.3 \%$ (Fig. 2b), exceeding significantly $(p<0.01)$ the random value $(53.6 \%)$. A separate DFA for adults correctly assigned $75.1 \%$, and a separate DFA for pups correctly assigned $66.9 \%$. In order of decreasing importance, the
Table 3 Values (means \pm SD) for the alarm call variables and body mass for age-sex classes of speckled ground squirrels $S$. suslicus

\begin{tabular}{|c|c|c|c|c|}
\hline \multirow[t]{2}{*}{ Variable } & \multicolumn{2}{|l|}{ Males } & \multicolumn{2}{|l|}{ Females } \\
\hline & $\begin{array}{l}\text { Adults } \\
N=26 \text { animals } \\
n=257 \text { calls }\end{array}$ & $\begin{array}{l}\text { Juveniles } \\
N=23 \text { animals } \\
n=228 \text { calls }\end{array}$ & $\begin{array}{l}\text { Adults } \\
N=26 \text { animals } \\
n=257 \text { calls }\end{array}$ & $\begin{array}{l}\text { Juveniles } \\
N=21 \text { animals } \\
n=207 \text { calls }\end{array}$ \\
\hline duration (ms) & $235 \pm 61$ & $222 \pm 48$ & $256 \pm 60$ & $220 \pm 47$ \\
\hline fo st $(\mathrm{kHz})$ & $9.64 \pm 0.56$ & $9.36 \pm 0.53$ & $9.25 \pm 0.88$ & $9.79 \pm 0.49$ \\
\hline fo centre $(\mathrm{kHz})$ & $9.55 \pm 0.51$ & $9.26 \pm 0.50$ & $9.21 \pm 0.79$ & $9.72 \pm 0.47$ \\
\hline fo end $(\mathrm{kHz})$ & $9.41 \pm 0.65$ & $9.16 \pm 0.77$ & $9.00 \pm 0.84$ & $9.80 \pm 0.62$ \\
\hline fo $\max (\mathrm{kHz})$ & $9.74 \pm 0.55$ & $9.57 \pm 0.54$ & $9.41 \pm 0.80$ & $10.02 \pm 0.54$ \\
\hline$f 0 \min (\mathrm{kHz})$ & $9.32 \pm 0.59$ & $8.94 \pm 0.65$ & $8.91 \pm 0.85$ & $9.53 \pm 0.50$ \\
\hline f peak $(\mathrm{kHz})$ & $9.57 \pm 0.53$ & $9.27 \pm 0.48$ & $9.22 \pm 0.78$ & $9.74 \pm 0.46$ \\
\hline bnd $(\mathrm{kHz})$ & $0.44 \pm 0.16$ & $0.49 \pm 0.22$ & $0.41 \pm 0.13$ & $0.52 \pm 0.21$ \\
\hline mass $(\mathrm{g})$ & $215 \pm 34$ & $88 \pm 37$ & $205 \pm 30$ & $74 \pm 21$ \\
\hline
\end{tabular}


Table 4 GLMM results for effects of factors "sex", "age", and "identity" on the alarm call variables in yellow ground squirrels $S$. fulvus

\begin{tabular}{|c|c|c|c|}
\hline \multirow[t]{2}{*}{ Variable } & \multicolumn{3}{|l|}{ Factor } \\
\hline & Sex & Age & Identity \\
\hline dur st-max & $\mathrm{F}_{1,884}=1.20 ; p=0.28$ & $F_{1,884}=6.02 *$ & $\boldsymbol{F}_{97,884}=76.79 * * *$ \\
\hline dur max-end & $\mathrm{F}_{1,884}=1.45 ; p=0.23$ & $F_{1,884}=36.75 * * *$ & $F_{97,884}=38.23 * * *$ \\
\hline fo st & $F_{1,884}=0.64 ; p=0.43$ & $F_{1,884}=37.08 * * *$ & $F_{97,884}=46.24 * * *$ \\
\hline fo $\max$ & $F_{1,884}=2.38 ; p=0.13$ & $F_{1,884}=0.21 ; p=0.65$ & $F_{97,884}=105.34 * * *$ \\
\hline fo end & $F_{1,884}=4.51^{*}$ & $F_{1,884}=6.03 *$ & $\boldsymbol{F}_{97,884}=42.02 * * *$ \\
\hline period $1-2$ & $F_{1,884}=8.09 * *$ & $F_{1,884}=10.36 * *$ & $\boldsymbol{F}_{97,884}=28.81 * * *$ \\
\hline df $\max 1-2$ & $F_{1,884}=5.69^{*}$ & $\boldsymbol{F}_{1,884}=24.65 * * *$ & $F_{97,884}=19.21 * * *$ \\
\hline$q 25$ & $F_{1,884}=0.01 ; p=0.94$ & $F_{1,884}=5.40 *$ & $\boldsymbol{F}_{\mathbf{9 7 , 8 8 4}}=\mathbf{5 5 . 8 8} * * *$ \\
\hline
\end{tabular}

period 1-2, df $\max 1-2, f 0 \max$, and $f 0$ end were mainly responsible for sex discrimination.

A DFA classifying alarm calls to age correctly assigned $88.2 \%$ (Fig. 2b), exceeding significantly $(p<0.01)$ the random value $(53.9 \%)$. A separate DFA for males correctly assigned $86.2 \%$ to age, and a separate one for females correctly assigned $90.4 \%$ to age. In order of decreasing importance, the $f 0$ st, dur st-max, dur max-end, and period 1-2 were mainly responsible for discrimination.

A DFA classifying alarm calls to individual correctly assigned $90.4 \%$ to individual (Fig. 2b), exceeding significantly $(p<0.01)$ the random value $(6.0 \%)$. A separate DFA for adults correctly assigned $90.3 \%$ to individual, a separate DFA for pups correctly assigned $94.7 \%$ to individual; a separate DFA for males correctly assigned $94.7 \%$ to individual, and a separate DFA for females correctly assigned $93.2 \%$ to individual. In order of decreasing importance, the $f 0$ max, dur st-max, $f 0$ st, and $q 25$ were mainly responsible for discrimination.

Therefore, in $S$. fulvus, assignment to sex was close to the random value; assignment to age was 1.6 times the random value, and assignment to individual as 15 times the random value. Figure $2 b$ summarizes the DFA results for within-species variation of alarm calls in $S$. fulvus. Like S. suslicus, individuality in S. fulvus calls was more pronounced than age-related cues or sex-related cues. However, in contrast to what we found in S. suslicus, we found no single variable important for discrimination of all three the categories: sex, age, and individual identity. Only two variables ( $f 0$ st and dur st-max) were among most important both in DFA for classification to individual and to age, and a single variable ( $f 0$ max) was among most important both in DFA for classification to individual and to sex. This suggests that, unlike that found in S. suslicus, sex- and age-related variation in the alarm call structure were based on acoustic cues unrelated to those responsible for the individual-level variation. Table 5 presents descriptive statistics for $S$. fulvus alarm call variables included into DFA and body mass for two age classes and two sex/gender classes.

Yellow-bellied marmots (M. flaviventris)

Table 6 presents GLMM results for the effects of "sex", "age", and "identity" on the alarm call variables in $M$. flaviventris. We found significant effects of identity on all variables and significant effects of sex or age for five of the eight variables. However, in only a few cases, these effects were comparable to the effects of identity (Table 6).

A DFA classifying alarm calls to sex correctly assigned $65.6 \%$ to sex (Fig. 2 c), exceeding significantly $(p<0.01)$ the random value $(57.3 \%)$. A separate DFA for adults correctly assigned $69.5 \%$ to sex, and one for pups correctly assigned $70.9 \%$ to sex. In order of decreasing importance, duration, $f$ peak, and $f 0$ end were mainly responsible for discrimination.

A DFA classifying alarm calls to age correctly assigned $88.9 \%$ to age (Fig. 2c), exceeding significantly $(p<0.01)$ the random value $(56.5 \%)$. A separate DFA for males correctly assigned $92.1 \%$ to age, and a separate DFA for females correctly assigned $89.8 \%$ to age. In order of decreasing importance, the duration, fo end, fo max, and fo min were mainly responsible for discrimination.

A DFA classifying alarm calls to individual correctly assigned $81.6 \%$ to individual (Fig. 2c), exceeding significantly $(p<0.01)$ the random value $(12.5 \%)$. A separate DFA for adults correctly assigned $77.9 \%$ to individual; one for pups correctly assigned $88 \%$ to individual; one for males correctly assigned $89.9 \%$ to individual, and a separate DFA for females correctly assigned $85.1 \%$ to individual. In order of decreasing importance, the duration, f0 st, $d$ ampl, bnd, and $f 0$ end were mainly responsible for discrimination.

Therefore, in $M$. flaviventris, assignment to sex was rather close to the random value; assignment to age was 1.5 times the random value, and assignment to individual was six times the random value. Figure $2 \mathrm{c}$ summarizes the DFA results for within-species variation of alarm calls in $M$. 
Table 5 Values (means \pm SD) for the alarm call variables and body weight for age-sex classes of yellow ground squirrels $S$. fulvus

\begin{tabular}{|c|c|c|c|c|}
\hline \multirow[t]{2}{*}{ Variable } & \multicolumn{2}{|l|}{ Males } & \multicolumn{2}{|l|}{ Females } \\
\hline & $\begin{array}{l}\text { Adults } \\
N=25 \text { animals } \\
n=247 \text { calls }\end{array}$ & $\begin{array}{l}\text { Juveniles } \\
N=25 \text { animals } \\
n=247 \text { calls }\end{array}$ & $\begin{array}{l}\text { Adults } \\
N=25 \text { animals } \\
n=250 \text { calls }\end{array}$ & $\begin{array}{l}\text { Juveniles } \\
N=25 \text { animals } \\
n=240 \text { calls }\end{array}$ \\
\hline dur st-max (ms) & $49 \pm 9$ & $53 \pm 9$ & $47 \pm 9$ & $51 \pm 7$ \\
\hline dur max-end (ms) & $20 \pm 3$ & $24 \pm 6$ & $18 \pm 3$ & $24 \pm 6$ \\
\hline fo st $(\mathrm{kHz})$ & $2.25 \pm 0.37$ & $2.64 \pm 0.31$ & $2.33 \pm 0.34$ & $2.65 \pm 0.25$ \\
\hline$f 0 \max (\mathrm{kHz})$ & $5.32 \pm 0.31$ & $5.19 \pm 0.45$ & $5.36 \pm 0.46$ & $5.41 \pm 0.43$ \\
\hline fo end $(\mathrm{kHz})$ & $1.70 \pm 0.21$ & $1.59 \pm 0.37$ & $1.86 \pm 0.24$ & $1.67 \pm 0.43$ \\
\hline period 1-2 (ms) & $224 \pm 34$ & $204 \pm 37$ & $206 \pm 25$ & $191 \pm 22$ \\
\hline df $\max 1-2(\mathrm{kHz})$ & $0.02 \pm 0.18$ & $-0.19 \pm 0.27$ & $-0.09 \pm 0.18$ & $-0.26 \pm 0.28$ \\
\hline$q 25(\mathrm{kHz})$ & $3.81 \pm 0.44$ & $3.87 \pm 0.37$ & $3.70 \pm 0.4$ & $3.97 \pm 0.34$ \\
\hline Mass (g) & $1343 \pm 207$ & $309 \pm 158$ & $856 \pm 138$ & $275 \pm 148$ \\
\hline
\end{tabular}

flaviventris. Thus, similar to the calls of the two squirrels, in $M$. flaviventris, cues that potentially facilitate individual discrimination were most prevalent, cues that potentially facilitate age discrimination are present, but not as prevalent, and there are few cues that potentially facilitate sex discrimination. Similar to $S$. suslicus but unlike $S$. fulvus, two variables of primary importance were responsible for discrimination in all the three DFA: to sex, to age, and to individual. These results suggest that in $M$. flaviventris, as in S. suslicus, the sex- and age-related variation in the alarm call structure was at least partially based on the same acoustic cues as the individual-level variation. Table 7 presents descriptive statistics for the alarm call parameters included into DFA and body mass for two age classes and two sex/gender classes of the $M$. flaviventris.

Comparison of within-species variation among the three sciurids

Figure 3 presents $\chi^{2}$-results comparing the DFA values of correct assignment to sex, age, and individual for $S$. suslicus, S. fulvus, and M. flaviventris. Correct assignment of calls to sex did not differ between $M$. flaviventris and $S$. fulvus and in both species, were significantly higher of those in S. suslicus. Consistently, we found that correct assignment of calls to age did not differ between $M$. flaviventris and $S$. fulvus and in both, were significantly higher than in S. suslicus. The value of correct assignment to individual was the highest in $S$. fulvus, the lowest in $S$. suslicus, and intermediate in M. flaviventris $(p<0.001$ for all comparisons; Fig. 3).

\section{Discussion}

The overall hierarchy of individual-, sex-, and age-related variation in alarm call structure was similar among the three studied species. The alarm calls of these three species permitted reliable discrimination among callers (Blumstein et al. 2004; Sloan and Hare 2006, 2008), but there is relatively less ability to encode age and very little information about sex. In these three species, the features encoding individual identity were more expressed than those encoding group-related features (sex or age). However, as expected, in S. suslicus, the individual-, sex-, and
Table 6 GLMM results for effects of factors "sex", "age", and "identity" on the alarm call variables in yellow-bellied marmots $M$. flaviventris

$F-F$-ratios of GLMM.

Significant effects are given in bold

${ }^{*}{ }_{-} p<0.05,{ }^{*}{ }_{-}-p<0.01,{ }^{*} *_{-}{ }_{-} p<$ 0.001

\begin{tabular}{|c|c|c|c|}
\hline \multirow[t]{2}{*}{ Variable } & \multicolumn{3}{|l|}{ Factor } \\
\hline & Sex & Age & Identity \\
\hline Duration & $F_{1,339}=2.75 ; p=0.10$ & $F_{1,339}=92.91 * * *$ & $F_{82,339}=16.01 * * *$ \\
\hline fo st & $F_{1,339}=12.61 * * *$ & $F_{1,339}=2.79 ; p=0.10$ & $F_{82,339}=66.40 * * *$ \\
\hline fo end & $F_{1,339}=4.28 *$ & $F_{1,339}=2.14 ; p=0.15$ & $F_{82,339}=28.37 * * *$ \\
\hline fo $\max$ & $F_{1,884}=9.80 * *$ & $F_{1,339}=13.39 ; * * *$ & $\boldsymbol{F}_{82,339}=45.07 * * *$ \\
\hline fo min & $F_{1,884}=5.64 *$ & $F_{1,339}=0.07 ; p=0.79$ & $\boldsymbol{F}_{82,339}=22.02 * * *$ \\
\hline f peak & $F_{1,884}=8.27 * *$ & $F_{1,339}=12.03 * * *$ & $\boldsymbol{F}_{82,339}=30.37 * * *$ \\
\hline$d a m p l$ & $F_{1,884}=1.83 ; p=0.18$ & $F_{1,339}=1.92 ; p=0.17$ & $\boldsymbol{F}_{82,339}=9.01 * * *$ \\
\hline bnd & $F_{1,884}=0.04 ; p=0.84$ & $F_{1,339}=15.10 * * *$ & $\boldsymbol{F}_{82,339}=10.02 * * *$ \\
\hline
\end{tabular}


Table 7 Values (means \pm SD) for the alarm call variables and body mass for age-sex classes of yellow-bellied marmots $M$. flaviventris

\begin{tabular}{|c|c|c|c|c|}
\hline \multirow[t]{2}{*}{ Variable } & \multicolumn{2}{|l|}{ Males } & \multicolumn{2}{|l|}{ Females } \\
\hline & $\begin{array}{l}\text { Adults } \\
N=12 \text { animals } \\
n=60 \text { calls }\end{array}$ & $\begin{array}{l}\text { Juveniles } \\
N=26 \text { animals } \\
n=129 \text { calls }\end{array}$ & $\begin{array}{l}\text { Adults } \\
N=26 \text { animals } \\
n=130 \text { calls }\end{array}$ & $\begin{array}{l}\text { Juveniles } \\
N=21 \text { animals } \\
n=105 \text { calls }\end{array}$ \\
\hline Duration (ms) & $23 \pm 6$ & $38 \pm 7$ & $23 \pm 5$ & $34 \pm 7$ \\
\hline fo st $(\mathrm{kHz})$ & $3.63 \pm 0.21$ & $3.59 \pm 0.38$ & $3.73 \pm 0.31$ & $3.97 \pm 0.36$ \\
\hline$f 0$ end $(\mathrm{kHz})$ & $3.35 \pm 0.32$ & $3.17 \pm 0.46$ & $3.5 \pm 0.34$ & $3.40 \pm 0.56$ \\
\hline$f 0 \max (\mathrm{kHz})$ & $3.75 \pm 0.25$ & $3.94 \pm 0.43$ & $3.89 \pm 0.35$ & $4.30 \pm 0.48$ \\
\hline$f 0 \min (\mathrm{kHz})$ & $2.49 \pm 0.34$ & $2.49 \pm 0.44$ & $2.67 \pm 0.35$ & $2.71 \pm 0.48$ \\
\hline f peak $(\mathrm{kHz})$ & $3.26 \pm 0.19$ & $3.39 \pm 0.38$ & $3.43 \pm 0.4$ & $3.73 \pm 0.38$ \\
\hline$d$ ampl (dB) & $-16.78 \pm 7.5$ & $-17.01 \pm 7.52$ & $-20.35 \pm 7.27$ & $-19.26 \pm 6.25$ \\
\hline bnd $(\mathrm{kHz})$ & $1.37 \pm 0.33$ & $1.36 \pm 0.33$ & $1.12 \pm 0.23$ & $1.45 \pm 0.45$ \\
\hline Mass (g) & $2976 \pm 1130$ & $866 \pm 430$ & $2572 \pm 713$ & $812 \pm 396$ \\
\hline
\end{tabular}

age-related characteristics were less prominent than in $S$. fulvus or M. flaviventris. In S. suslicus and M. flaviventris, acoustic features most important for encoding individuality also encode sex and age, suggesting that the individuallevel variation is involved in sex- and age-related discrimination. Distinctively, in S. fulvus, the sex- and age-related variation was based on unique parameters not used for individual discrimination. Therefore, we can conclude that at least in two ground-dwelling sciurids, the cues encoding the identity of the callers are integral characteristics that are used also for encoding sex and age. At the same time, our data confirmed our hypothesis that, in the two more social species, M. flaviventris and S. fulvus, alarm calls should provide more cues about caller identity, age, and sex than in the less social species ( $S$. suslicus).

In this study, we compared species' DFA results for encoding identity, age, and sex of alarm callers. Because calls are species-specific, we were unable to measure the

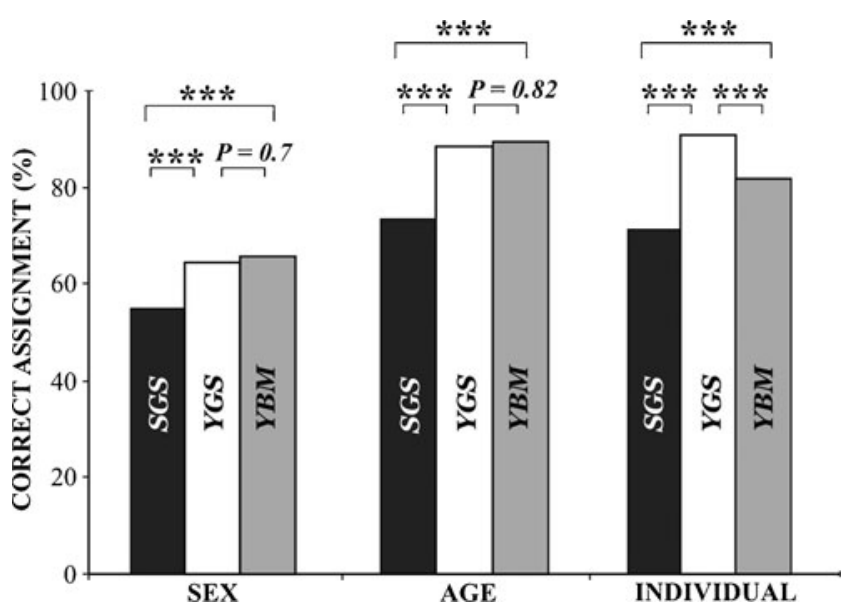

Fig. 3 Comparison between DFA values of correct assignment to sex, age, and individual for speckled ground squirrels $S$. suslicus (SGS), yellow ground squirrels $S$. fulvus $(Y G S)$, and yellow-bellied marmots M. flaviventris $(Y B M) . * * *-p<0.001, \chi^{2}$ test same acoustic variables. DFA results are influenced by the similarity of the acoustic variables, the number of the variables included into DFAs, and the number of groups to be discriminated. In the current study, we focused on similar numbers of individuals within each age-sex class and used the same number of acoustic variables per species. These variables were selected by being unrelated and distinctive. Thus, we believe that our DFA results are a valid way to make comparisons among species.

For each individual, we analyzed alarm calls from a single recording session. This experimental design modeled naturally occurring predatory events, where receivers would normally acquire information about attributes of a caller from a single calling bout. Individually discriminable alarm calls could be important to provide information on how many individuals are simultaneously calling (Blumstein et al. 2004; Sloan and Hare 2006, 2008) or may allow tracking of predator movements (Thompson and Hare 2010). However, in S. suslicus and S. fulvus, the individually distinctive calls could hardly be used to detect false alarm calls and remember the caller. For $S$. suslicus and S. fulvus, individuality decreased between calling bouts recorded with time space of 1 year. Reliable identification dropped to as few as $27 \%$ to $30 \%$ of individuals (Matrosova et al. 2009, 2010a), although this was still greater than expected by chance (Matrosova et al. 2009, 2010a).

The stability of individual acoustic signatures varies between species. Individuality decreases over time in rutting calls of male fallow deer Dama dama (Briefer et al. 2010), "boom" calls of male great bitterns Botaurus stellaris (Puglisi and Adamo 2004), and chatter calls of bald eagles Haliaeetus leucocephalus (Eakle et al. 1989). In some species, individuality is stable but varies with changes in the social environment, as seen in a few captive marmoset species (Jones et al. 1993; Snowdon and Elowson 1999; Rukstalis et al. 2003) and in common loons Gavia immer (Walcott et al. 2006). Unlikely, individuality is remarkably 
stable across years in calls of eagle owls Bubo bubo (Lengagne 2001; Grava et al. 2008) and in the duets of red-crowned cranes Grus japonensis (Klenova et al. 2009). Studying the stability of individual acoustic signatures in alarm calls should be extended on a wide range of species of ground-dwelling sciurids, especially in relation to probable use of acoustic fingerprinting as a non-invasive tool for censuses in the field (Terry et al. 2005; Blumstein and Fernández-Juricic 2010; Schneiderová and Policht 2010; Pollard et al. 2010).

Our data suggest that age difference in body mass (Tables 3,5, and 7), reported previously as one of the main determinants of the fundamental frequency and duration in mammalian calls (Morton 1977; Fitch and Hauser 2002; Matrosova et al. 2007), was relatively less important than variation in the vocal anatomy and/or vocal tuning among individuals. In rapidly maturing ground squirrels, alarm call fundamental frequencies do not differ between juvenile and older animals (Matrosova et al. 2007; Swan and Hare 2008; Volodina et al. 2010). By contrast, in marmots, the fundamental frequency of alarm calls is noticeably higher in juveniles than in adults and thus can indicate the age (Nesterova 1996; Blumstein and Munos 2005; Nikol'skii 2007). Fundamental frequency-based cues to age in marmots might be functionally important in facilitating parental care (Blumstein and Daniel 2004).

In all three species, acoustic cues to sex were least expressed compared with those encoding individual identity and age, probably because knowing a caller's sex is not important in a predatory context. Potentially, the cues to sex should be important in other social contexts, such as post-copulatory mate guarding. Alarm calling during post-copulatory mate guarding has been reported in male Formosan squirrels Callosciurus erythraeus thaiwanensis and Columbian ground squirrels Spermophilus columbianus (Tamura 1995; Manno et al. 2007), but not in any of our species. In other species, emitting alarm calls in mating-related contexts have been reported for male topi antelope Damaliscus lunatus which use alarm snorts for retaining estrous females on their territories to secure mating opportunities (Bro-Jorgensen and Pangle 2010) and among birds for ornamented male fowl, Gallus gallus (Wilson et al. 2008).

Our results suggest that alarm calls can be reliably discriminated on the basis of individual characteristics in all three species and that the individual-based characteristics appeared to be more prominent than the variation allowing identification of sex and age categories. This potential was related to a species' social structure. However, considering the fact that all species have a rather low level of sociality, it would be interesting to obtain similar data on more social marmot species, such as Alpine marmots (Marmota marmota) as well as highly social prairie dogs (Cynomys spp.).
Acknowledgments We thank S.A. Shilova, A.V. Tchabovsky, L.E. Savinetskaya, O.N. Shekarova, A.F. Babitsky, O. Munos, and N.A. Vasilieva for help with data collection, and V.S. Lebedev and A.A. Lisovsky for help with statistics. We are sincerely grateful to the two anonymous reviewers for very constructive comments. During our work, we adhered to the "Guidelines for the treatment of animals in behavioural research and teaching" (Anim Behav, 2006, 71:245-253) and to the laws of USA and of Russian Federation, the countries where the research was conducted. Research protocol ARC \#2001191-01 was approved by the University of California, Los Angeles (UCLA) Animal Care Committee on 13 May 2002 and renewed annually. Research protocol \#2008-03 was approved by the Committee of bio-ethics of Lomonosov Moscow State University. This study was supported by the Russian Foundation for Basic Research, grant 09-04-00416 (for VAM, IAV, EVV) and by generous support by UCLA Division of Life Sciences and Academic Senate (for DTB).

Open Access This article is distributed under the terms of the Creative Commons Attribution Noncommercial License which permits any noncommercial use, distribution, and reproduction in any medium, provided the original author(s) and source are credited.

\section{References}

Armitage KB (1982) Yellow-bellied marmot. In: Davis DE (ed) CRC handbook of census methods for terrestrial vertebrates. CRC, Boca Raton, pp 148-149

Armitage KB (1991) Social and population dynamics of yellow-bellied marmots: results from long-term research. Annu Rev Ecol Syst 22:379-407

Armitage KB (1999) Evolution of sociality in marmots. J Mammal 80:1-10

Blumstein DT (2007) The evolution of alarm communication in rodents: structure, function, and the puzzle of apparently altruistic calling in rodents. In: Wolff JO, Sherman PW (eds) Rodent societies. U Chicago Press, Chicago, pp 317-327

Blumstein DT, Armitage KB (1997) Does sociality drive the evolution of communicative complexity? A comparative test with grounddwelling sciurid alarm calls. Am Nat 150:179-200

Blumstein DT, Daniel JC (2004) Yellow-bellied marmots discriminate among the alarm calls of individuals and are more responsive to the calls from juveniles. Anim Behav 68:1257-1265

Blumstein DT, Fernández-Juricic E (2010) A primer of conservation behavior. Sinauer, Sunderland

Blumstein DT, Munos O (2005) Individual, age and sex-specific information is contained in yellow-bellied marmot alarm calls. Anim Behav 69:353-361

Blumstein DT, Verneyre L, Daniel JC (2004) Reliability and the adaptive utility of discrimination among alarm callers. Proc $\mathrm{R}$ Soc B 271:1851-1857

Bokshtein FM, Kucheruk NV, Tupikova NV (1989) The use of territory and the interrelationships in the yellow ground squirrels (Citellus fulvus Licht, 1823). Russ J Ecol 20(5):45-50 (in Russian)

Briefer E, Vannoni E, McElligott AG (2010) Quality prevails over identity in the sexually selected vocalisations of an ageing mammal. BMC Biol 8:35. doi:10.1186/1741-7007-8-35

Bro-Jorgensen J, Pangle WM (2010) Male topi antelopes alarm snort deceptively to retain females for mating. Am Nat 176:E33-E39. doi:10.1086/653078

Charif RA, Mitchell S, Clark CW (1995) Canary 1.2 User's Manual. Cornell Laboratory of Ornithology, Ithaca, New York

Cheney DL, Seyfarth RM (1990) How monkeys see the world. University of Chicago Press, Chicago 
Digweed SM, Rendall D (2009a) Predator-associated vocalizations in North American red squirrels, Tamiasciurus hudsonicus: are alarm calls predator specific? Anim Behav 78:1135-1144

Digweed SM, Rendall D (2009b) Predator-associated vocalizations in North American red squirrels (Tamiasciurus hudsonicus): to whom are alarm calls addressed and how do they function? Ethology 115:1190-1199

Durbin LS (1998) Individuality in the whistle call of the Asiatic wild dog Cuon alpinus. Bioacoustics 9:197-206

Eakle WL, Mannan RW, Grubb TG (1989) Identification of individual breeding eagles by voice analysis. J Wildl Manage 53:450-455

Fitch WT, Hauser MD (2002) Unpacking "honesty": vertebrate vocal production and the evolution of acoustic signals. In: Simmons A, Fay RR, Popper AN (eds) Acoustic communication, Springer handbook of auditory research. Springer, New York, pp 65-137

Frommolt K-H, Goltsman ME, Macdonald DW (2003) Barking foxes, Alopex lagopus: field experiments in individual recognition in a territorial mammal. Anim Behav 65:509-518

Grava T, Mathevon N, Place E, Balluet P (2008) Individual acoustic monitoring of the European eagle owl Bubo bubo. Ibis 150:279-287

Hanson MT, Coss RG (2001) Age differences in the response of California ground squirrels (Spermophilus beecheyi) to conspecific alarm calls. Ethology 107:259-275

Hare JF (1998) Juvenile Richardson's ground squirrels, Spermophilus richardsonii, discriminate among individual alarm callers. Anim Behav 55:451-460

Hasson O (1991) Pursuit-deterrent signals: communication between prey and predators. Trends Ecol Evol 6:325-329

Hurlburt RT (2003) Comprehending behavioral statistics, 3rd edn. Wadsworth/Thomson Learning, Belmont

Ismagilov MI (1969) Yellow ground squirrel-Citellus fulvus. In: Sludskiy AA (ed) Mammals of Kazakhstan, v. 1, Rodents (marmots and ground squirrels). Alma-Ata, Nauka, pp 120-159 (in Russian)

Jones BS, Harris DHR, Catchpole CK (1993) The stability of the vocal signature in phee calls of the common marmoset Callithrix jacchus. Am J Primatol 31:67-75

Kashkarov D, Lein L (1927) The yellow ground squirrel of Turkestan, Cynomys fulvus oxianus Thomas. Ecology 8:63-72

Klenova AV, Volodin IA, Volodina EV (2009) Examination of pairduet stability to promote long-term monitoring of the endangered red-crowned crane (Grus japonensis). J Ethol 27:401-406

Leger WD, Berney-Key SD, Sherman PW (1984) Vocalizations of Belding's ground squirrels (Spermophilus beldingi). Anim Behav 32:753-764

Lengagne $\mathrm{T}$ (2001) Temporal stability in the individual features in the calls of eagle owls (Bubo bubo). Behaviour 138:1407-1419

Macromedia (1995) SoundEdit 16. Macromedia, San Francisco

Manno TG, Nesterova AP, Debarbieri LM, Kennedy SE, Wright KS, Dobson FS (2007) Why do male Columbian ground squirrels give a mating call? Anim Behav 74:1319-1327

Matrosova VA, Volodin IA, Volodina EV, Babitsky AF (2007) Pups crying bass: vocal adaptation for avoidance of age-dependent predation risk in ground squirrels? Behav Ecol Sociobiol 62:181-191

Matrosova VA, Volodin IA, Volodina EV (2008) Does kinship affect the alarm call structure in the yellow ground squirrel Spermophilus fulvus? Lynx (Praha) n s 39:295-303

Matrosova VA, Volodin IA, Volodina EV (2009) Short-term and longterm individuality in speckled ground squirrel alarm calls. J Mammal 90:158-166

Matrosova VA, Volodin IA, Volodina EV, Vasilieva NA, Kochetkova AA (2010a) Between-year stability of individual alarm calls in the yellow ground squirrel Spermophilus fulvus. J Mammal 91:620-627
Matrosova VA, Volodin IA, Volodina EV, Vasilieva NA (2010b) Stability of acoustic individuality in the alarm calls of wild yellow ground squirrels Spermophilus fulvus and contrasting calls from trapped and free-ranging callers. Naturwissenschaften 97:707-715

McCowan B, Hooper SL (2002) Individual acoustic variation in Belding's ground squirrel alarm chirps in the High Sierra Nevada. J Acoust Soc Am 111:1157-1160

Morton ES (1977) On the occurrence and significance of motivationstructural rules in some bird and mammal sounds. Am Nat 111:855869

Nesterova NL (1996) Age-dependent alarm behavior and response to alarm call in bobac marmots (Marmota bobac Mull). In: Le Berre M, Ramousse R, Le Guelte L (eds) Biodiversity in marmots. International Network on Marmots, Moscow-Lyon, pp 181-186

Nikol'skii AA (2007) A comparative analysis of the alarm call frequency in different age rodent groups. Zoologicheskii Zhurnal 86:499-504 (in Russian)

Nikol'skii AA, Suchanova MV (1994) Individual variability of alarm call in steppe marmot (Marmota bobac Mull., 1776). In: Rumiantsev VY (ed) Actual problems of marmots investigation. Moscow, ABF Publishing House, pp 169-181

Owings DH, Loughry WJ (1985) Variation in snake-elicited jumpyipping by black-tailed prairie dogs: ontogeny and snake specificity. Z Tierpsychol 70:177-200

Pollard KA, Blumstein DT, Griffin SC (2010) Pre-screening acoustic and other natural signatures for use in noninvasive individual identification. J Appl Ecol 47:1103-1109

Puglisi L, Adamo C (2004) Discrimination of individual voices in male great bitterns (Botaurus stellaris) in Italy. Auk 121:541547

Rendall D, Owren MJ, Ryan MJ (2009) What do animal signals mean? Anim Behav 78:233-240

Rukstalis M, Fite JE, French JA (2003) Social change affects vocal structure in a callitrichid primate (Callitrix kuhlii). Ethology 109:327-340

Schneiderová I, Policht R (2010) Alarm calls of the European ground squirrel Spermophilus citellus and the Taurus ground squirrel $S$. taurensis encode information about caller identity. Bioacoustics 20:29-43

Shelley EL, Blumstein DT (2005) The evolution of vocal alarm communication in rodents. Behav Ecol 16:169-177

Sherman PW (1977) Nepotism and the evolution of alarm calls. Science 197:1246-1253

Sherman PW (1985) Alarm calls of Belding's ground squirrels to aerial predators: nepotism or self-preservation? Behav Ecol Sociobiol 17:313-323

Shilova SA, Tchabovsky AV, Popov VS (2006) Patterns of colony formation while occupying new patches in long-teeth ground squirrel (Spermophilus fulvus Licht., 1823). Bulletin of Moscow Society of Nature Explorers, Dept of Biology 111(5):71-75, in Russian

Sloan JL, Hare JF (2006) Adult Richardson's ground squirrels (Spermophilus richardsonii) ignore rate changes in juvenile alarm calls: age-differential response urgency perception? Ethology 112:896-902

Sloan JL, Hare JF (2008) The more the scarier: adult Richardson's ground squirrels (Spermophilus richardsonii) assess response urgency via the number of alarm signalers. Ethology 114:436-443

Snowdon CT, Elowson AM (1999) Pygmy marmosets modify call structure when paired. Ethology 105:893-908

Solow AR (1990) A randomization test for misclassification probability in discriminant analysis. Ecology 71:2379-2382

Swan DC, Hare JF (2008) Signaler and receiver ages do not affect responses to Richardson's ground squirrel alarm calls. J Mammal 89:889-894 
Tamura N (1995) Postcopulatory mate guarding by vocalization in the Formosan squirrel. Behav Ecol Sociobiol 36:377-386

Tchabovsky AV (2005) Sociality of ground squirrels: effect of body size and habitat type. Bulletin of Moscow Society of Nature Explorers, Dept of Biology 110(4):80-88 (in Russian)

Terry AMR, Peake TM, McGregor PK (2005) The role of vocal individuality in conservation. Frontiers in Zoology 2(10): doi:10.1186/1742-9994-2-10

Thompson AB, Hare JF (2010) Neighbourhood watch: multiple alarm callers communicate directional predator movement in Richardson's ground squirrels, Spermophilus richardsonii. Anim Behav 80:269-275

Torriani MV, Vannoni E, McElligott AG (2006) Mother-young recognition in an Ungulate hider species: a unidirectional process. Am Nat 168:412-420

Vasilieva NA, Savinetskaya LE, Tchabovsky AV (2009) Large body size and short period of activity do not impede fast growth in the long-teeth ground squirrel (Spermophilus fulvus). Zoologicheskii Zhurnal 88:339-343 (in Russian)
Volodin IA (2005) Individuality in the alarm call of the speckled suslik Spermophilus suslicus (Rodentia, Sciuridae). Zoologicheskii Zhurnal 84:228-235 (in Russian)

Volodin IA, Volodina EV, Matrosova VA, Savinetskaya LE, Shekarova ON, Voytsik VA (2008) Population density does not affect the alarm call characteristics in the speckled ground squirrel Spermophilus suslicus. Lynx (Praha), n s 39:333-342

Volodina EV, Matrosova VA, Volodin IA (2010) An unusual effect of maturation on the alarm call fundamental frequency in two species of ground squirrels. Bioacoustics 20:87-98

Walcott C, Mager JN, Piper W (2006) Changing territories, changing tunes: male loons, Gavia immer, change their vocalizations when they change territories. Anim Behav 71:673-683

Wilson DR, Bayly KL, Nelson XJ, Gillings M, Evans CS (2008) Alarm calling best predicts mating and reproductive success in ornamented male fowl, Gallus gallus. Anim Behav 76:543554

Woodland DJ, Jafaar Z, Knight ML (1980) The "pursuit deterrent" function of alarm signals. Am Nat 115:748-753 